\title{
Effect of pregnancy induced hypertension on adverse perinatal outcomes in Tigray regional state, Ethiopia: a prospective cohort study
}

Abadi Kidanemariam Berhe ${ }^{1,2^{*}}$, Abiodun O. llesanmi ${ }^{3}$, Christopher O. Aimakhu ${ }^{3}$ and Afework Mulugeta ${ }^{4}$

\begin{abstract}
Background: The prevalence of pregnancy-induced hypertension in Ethiopia ranges from 2.2 to $18.3 \%$. However, so far little is known about the adverse perinatal outcomes of pregnancy-induced hypertension in Tigray regional state, Ethiopia. Therefore, the objective of this study was to assess the effect of pregnancy-induced hypertension on adverse perinatal outcomes in Tigray Regional State, Ethiopia.

Methods: a prospective cohort study was conducted on a total sample of 782 pregnant women attending antenatal care in hospitals of Tigray regional state, Ethiopia. Pregnant mothers diagnosed with PIH during the data collection period in the selected hospitals were included as exposed group and normotensive women were also enrolled as a control group. This study addresses women diagnosed with preeclampsia, eclampsia and gestational hypertension between 28 and 35 weeks of gestation. Data were collected using an interviewer-administered questionnaire and review of their medical records from February 2018, to February 2019. The adverse perinatal outcome event includes low birth weight, birth asphyxia, small for gestational age, preterm delivery, admission to neonatal intensive care unit and perinatal death. A modified Poisson regression model with robust standard errors was used to analyze relative risk.
\end{abstract}

Results: In this study, the overall incidence of adverse perinatal outcome was higher among women with pregnancy-induced hypertension than normotensive women (66.4\% vs 22.2\%). After adjusted for confounders women with pregnancy-induced hypertension were born babies with a higher risk of low birth weight (adjusted RR $(95 \% \mathrm{Cl})=5.1(3.4,7.8))$, birth asphyxia $(\mathrm{aRR}=2.6(1.9,3.8))$, small for gestational age $(\mathrm{aRR}=3.3(2.3,4.6))$, preterm delivery $(a R R=5.2(3.4,7.9))$, stillbirth $(a R R=3.46(1.40,8.54))$, admission to neonatal intensive care unit $(a R R=5.1(3.1,8.4))$ and perinatal death $(\mathrm{aRR}=3.6(1.8,7.4))$ compared to normotensive pregnant women.

Conclusions: Higher incidences of adverse perinatal outcomes occurred among women pregnancy-induced hypertension in Tigray regional state, Ethiopia. Hence, health care providers should strengthen prevention, early diagnosis and prompt management of pregnancy-induced hypertension to reduce adverse perinatal outcomes of pregnancy-induced hypertension.

Keywords: Adverse perinatal outcomes, Pregnancy-induced hypertension, Tigray, Ethiopia

\footnotetext{
* Correspondence: abadik021@gmail.com

${ }^{1}$ College of Medicine and Health Sciences, Adigrat University, Tigray, Ethiopia

${ }^{2}$ Pan African University Institute for Life and Earth Sciences, University of

Ibadan, Ibadan, Nigeria

Full list of author information is available at the end of the article
}

(c) The Author(s). 2019 Open Access This article is distributed under the terms of the Creative Commons Attribution 4.0 International License (http://creativecommons.org/licenses/by/4.0/), which permits unrestricted use, distribution, and reproduction in any medium, provided you give appropriate credit to the original author(s) and the source, provide a link to the Creative Commons license, and indicate if changes were made. The Creative Commons Public Domain Dedication waiver (http://creativecommons.org/publicdomain/zero/1.0/) applies to the data made available in this article, unless otherwise stated. 


\section{Introduction}

Pregnancy-induced hypertension (PIH) was defined as new hypertension that appears at 20 weeks or more gestational age of pregnancy with or without proteinuria, which includes gestational hypertension, preeclampsia, and eclampsia [1-3]. Hypertension is defined as a sustained systolic BP $\geq 140 \mathrm{mmHg}$ or diastolic $\mathrm{BP} \geq 90 \mathrm{mmHg}$ based on the average of at least two measurements, using the same arm [4]. Globally, $\mathrm{PIH}$ is a significant public health threat both in developed and developing countries contributing to high perinatal deaths [5]. PIH complicates $2-8 \%$ of pregnancies in the Western world [6]. However, the magnitude of PIH in developing countries reaches up to $16.7 \%$ [7]. Additionally, the available literature in Ethiopia showed a high burden of $\mathrm{PIH}$ which ranges from 2.23 to $18.25 \%$ [8-13]. Similarly, according to the finding of a study conducted in Tigray regional state, PIH was among the leading obstetric causes of maternal mortality in the region and the prevalence of $\mathrm{PIH}$ reported in this study was $8.1 \%$, this was higher than the national pooled prevalence of $\mathrm{PIH}$ (6.29\%) [14-16].

Different studies conducted in developed and developing countries on adverse perinatal outcomes of pregnancyinduced hypertension showed that PIH was associated with higher rates of morbidity and mortality such as preterm delivery, low birth weight, birth asphyxia, stillbirth and early neonatal death [17-22]. Similarly, studies conducted in Africa revealed that adverse perinatal outcomes such as perinatal death, low birth weight, preterm birth, and birth asphyxia were associated with PIH [23-25]. However, the risk and incidence of adverse perinatal outcomes of PIH vary across countries, populations and ethnic-geographic areas.

In Ethiopia, despite the inconsistent findings on the incidence of adverse perinatal outcomes across the studies, the available limited studies revealed a higher incidence of low birth weight, stillbirth, early neonatal death, birth asphyxia and preterm birth among women with PIH [26, 27]. However, so far little is known about the adverse perinatal outcomes of $\mathrm{PIH}$ in Tigray regional state. The available studies conducted in Ethiopia were descriptive they did not address the association between PIH and adverse perinatal outcomes. Additionally, most of the studies conducted in Ethiopia were used retrospective study design which might have introduced bias due to incompleteness and misclassification of the data at the health facilities. Thus, this prospective cohort study helps to explore the effect of PIH on the adverse perinatal outcomes and reduces the bias-related with incompleteness and misclassification of the data.

\section{Methods}

Study setting, design and period

A prospective cohort study was conducted in multiple hospitals of Tigray regional state. Tigray regional state is located in the northern part of Ethiopia bordered by Eritrea to the north, Sudan to the west, Afar region to the east and Amhara region to the south. The source population for this study was all pregnant women who attend antenatal care at general hospitals located in Tigray from February 2018 to February 2019. General hospitals provide outpatient and inpatient services to the general population which includes medical, surgical, pediatric, accident and emergency services, maternal and child health $(\mathrm{MCH})$, and obstetric and gynecological care, and other relevant services. In addition, general hospitals serve as a referral center to primary health care units. There are fifteen general hospitals in Tigray regional state from those the following eight hospitals entirely distributed in the region namely Lemlem Carl, Mekelle, Adigrat, Adwa, Saint Marry Axum, Suhul Shire, and Kahsay Abera hospitals were included in this study. Those selected hospitals can represent the larger region since more than $50 \%$ of the hospitals in the region were included in this study. General hospitals provide both basic and comprehensive emergency obstetric and newborn care. The average number of delivery in each hospital is around 1600 per year. All the hospitals included in this study provide comprehensive diagnostic and management services for hypertensive disorders of pregnancy starting from the mild form of gestational hypertension to the severe forms of preeclampsia/eclampsia.

\section{Inclusion and exclusion criteria}

Women with PIH and normotensive women in each antenatal care clinic of the hospitals were enrolled to study by reviewing their blood pressure level and proteinuria. Pregnancy-induced hypertension was defined as new hypertension (systolic BP $\geq 140 \mathrm{mmHg}$ and/or diastolic $\mathrm{BP} \geq 90 \mathrm{mmHg}$ ) that appears at 20 weeks or more gestational age of pregnancy with or without proteinuria (includes preeclampsia, eclampsia, and gestational hypertension). Pregnant mothers diagnosed with PIH during the data collection period in the selected antenatal care clinic of the hospitals were included as exposed participants and women without PIH during the same period were also enrolled as a non-exposed participant. Pregnant women with chronic hypertension, critically ill women who could not give consent, women who could not respond to the interview and those pregnant women likely to become "lost" e.g., planning to move, unwilling to return for the prospective follow up period were excluded from this study at the time of enrollment. There were no other restrictions (like maternal age, singleton pregnancies, etc.). 


\section{Sample size determination and sampling procedure}

A double population proportion formula was used to calculate the sample size. The maximum sample for this study was calculated from the outcome variable stillbirth by considering the following assumptions; two-sided confidence level of $95 \%$, the power level $=80 \%, r=$ the ratio of exposed to unexposed group 1 to $2, \mathrm{p}_{1}=$ proportion of stillbirth among women with $\mathrm{PIH} 5.4 \%$ [23], p2 = proportion of stillbirth among normotensive pregnant women 1.3\%) [23]. With the consideration of a $10 \%$ loss to follow up a total of 798 study participants (266 participants with PIH and 532 normotensive participants) were finally included in this study.

From a total of fifteen general hospitals providing maternal health services like antenatal care, delivery and postnatal care services in Tigray regional state, randomly eight hospitals were selected using a simple random sampling technique. The calculated sample size was proportionally allocated to selected hospitals based on the number of pregnant mothers attending antenatal care in each hospital. Women with PIH were recruited consecutively until we get the required sample and two normotensive women next to diagnosed PIH cases were selected by a systematic sampling method using antenatal care registration as a frame list.

\section{Data collection instruments and quality assurance}

A structured questionnaire containing information on socio-demographic characteristics (maternal age, residence, educational status, and employment), obstetric and reproductive health history information's like gravidity, prior history of $\mathrm{PIH}$, maternal undernutrition $((\mathrm{MUAC}<23 \mathrm{~cm})$, history of anemia, current PIH status, and perinatal outcomes were used to collect the data. Wealth index of participants was assessed using socioeconomic variables like durable asset ownership, ownership of housing, type of floor and roof materials, ownership of farmland, farm animals, number of people in a household, number of rooms in the household, access to utilities and infrastructure (sanitation facility and source of water supply). The questionnaire was prepared by reviewing research articles, demographic health survey (DHS) tools, WHO survey tools and published works on PIH then adapted to the local context [21, 23, 27-36]. Overall the questionnaire of this study was initially prepared in English version and translated to the local language called Tigrigna by a language expert and back converted again to English by another person to check the consistency.

Midwives and nurses having experience in research assistance were involved in the data collection and supervision. Training was provided for all data collectors and supervisors before the commencement of the actual data collection. The training focused on the objectives of the study, ethical issues, interviewing techniques, inclusion criteria of the study, follow up procedures of the study and overall contents of the data collection instrument. Before starting the actual data collection, a pretest was done for the data collection instruments. Necessary corrections on the data collection instrument were made based on the result of the pretest.

\section{Data collection procedure}

The recruitment of study participants was carried out from February to November 2018. Women who fulfill the inclusion criteria were enrolled in the study during antenatal care. Participants were enrolled at $28-35$ weeks of their gestational age. The follow-up period varies between participants depending on the time of enrollment to the study and the gestational age at enrollment. However, the overall follow up period was from February 2018 to February 2019. All selected women were followed by data collectors prospectively through pregnancy, delivery and the postnatal period to assess adverse perinatal outcomes of PIH. Data regarding maternal socio-demographic characteristics, medical and obstetric history using an interviewer-administered questionnaire and PIH status using medical records were collected during enrollment. At the second phase within 24 $h$ of delivery, information about the adverse perinatal outcomes such as birth asphyxia, birth weight, and gestational age at delivery, stillbirth and early neonatal death were collected from medical records. During the third phase within the postnatal period of three to 7 days, data regarding early neonatal death and early neonatal admission to NICU were collected from medical records. The definition of outcomes was based on world health organization and other related literature [37-39]. Close supervision and checking of filled-in questionnaires were done by the field supervisors deployed with the data collectors. The overall data collection process was coordinated and supervised by the principal investigator.

\section{Definition of outcomes}

The adverse perinatal outcome was defined as a newborn with the occurrence of any of the following outcomes low birth weight, birth asphyxia, small for gestational age, preterm delivery, admission to neonatal intensive care unit and perinatal death. Birth asphyxia was defined as a baby with trouble in breathing (gasping or breathing very irregularly or no breathing). Stillbirth was defined as a baby born with no signs of life at or after 28 weeks' gestation [37]. Small for gestational age of pregnancy defined as a birth weight of newborn below the tenth percentile of weight distribution at the specified gestational age of a pregnancy [39]. Low birth weight was defined as a baby with a birth weight less 
than $2500 \mathrm{~g}$ [38]. Preterm delivery was defined as the delivery of the baby below 37 weeks gestation [38]. Low Apgar score defined as a newborn baby with an Apgar score of less than 7 at 1 and 5 min.

\section{Data analyses methods}

Descriptive statistics, frequencies and percentage for categorical variable and summary statistics for continuous data (mean with standard deviation in normally distributed data or median with IQR if the data was not normally distributed) were used to characterize the study population. The normality distribution test was done using the Kolmogorov-Smirnov test and we considered as normally distributed if $p$-value $>0.05$. Independent $t-$ test was used to assess the mean difference between groups. The wealth index of participants was computed using principal component analysis (PCA) from socioeconomic variables. Due to the convergent problem in log-binomial regression analysis, a modified Poisson regression model with robust standard errors was used to calculate relative risk using STATA version 14 software (research resource identifiers (RRIDs: SCR 012763)) to identify the effect of PIH on adverse perinatal outcomes. Maternal age, wealth status, educational status, residence, gravidity, type of pregnancy (single or multiple births) and mode of delivery, anemia status, maternal undernutrition variables were controlled in the statistical models. After adjusted for confounders relative risk with $95 \%$ confidence interval and $p$-value $<0.05$ was considered to declare statistical significance.

\section{Results}

Socio-demographic characteristics of study participants

Overall a total of 260(97.7\%) women with PIH and 522(98.1\%) normotensive pregnant women had completed the study (Fig. 1). The reasons for the loss-to-follow-up study were traveling to other places for assistance during pregnancy and delivery. The mean maternal age of women

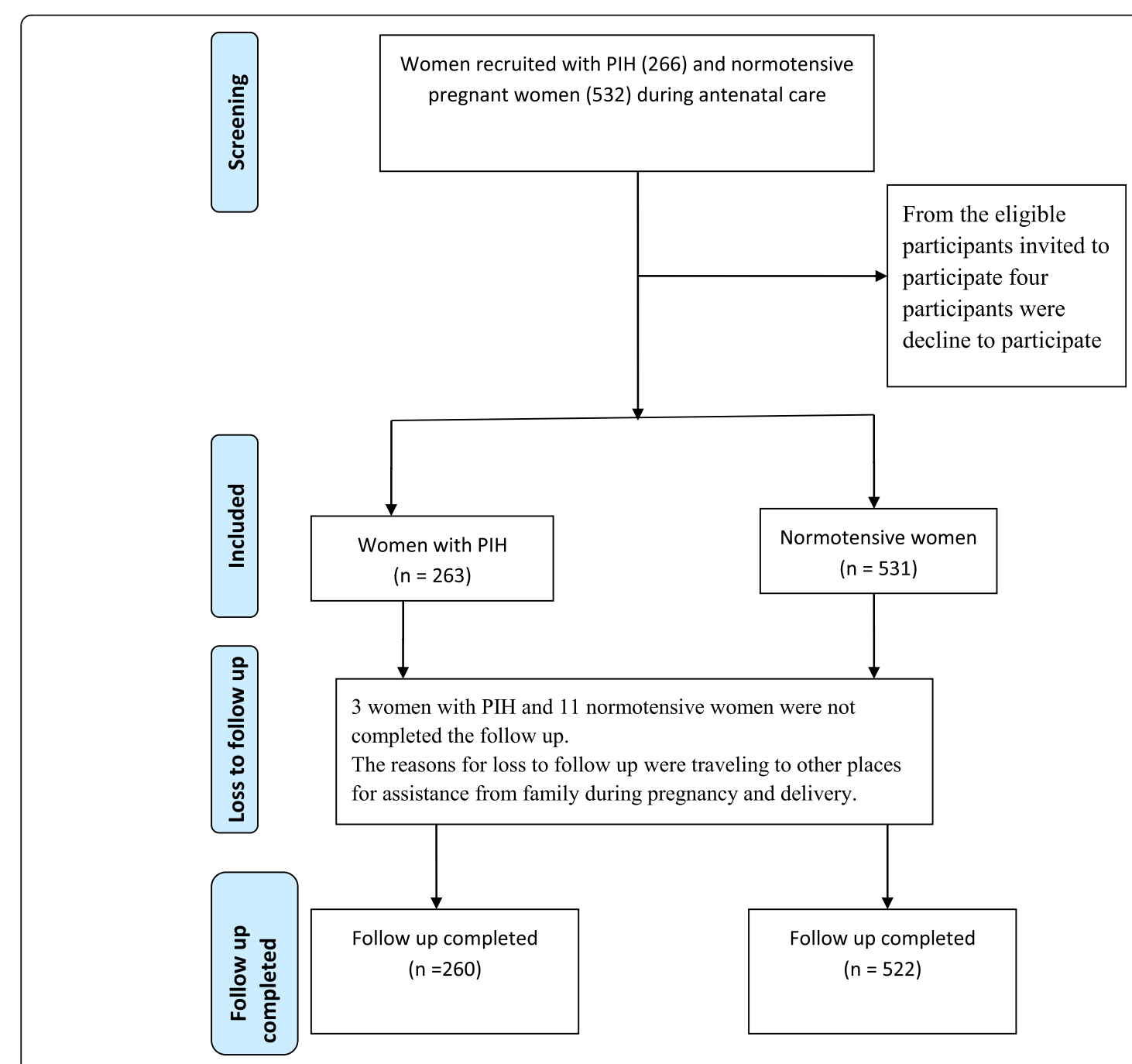

Fig. 1 A flow diagram of study participants 
with PIH and normotensive women was more or less similar (27.27 vs 27.34 years respectively). Women with $\mathrm{PIH}$ were more likely residing in rural areas than normotensive women (31.5\% vs $16.7 \%)$. The proportion of primigravidas were more likely higher among women with $\mathrm{PIH}$ than normotensive women (41.2\% vs $31.8 \%)$. In addition, women PIH were less likely to be in the highest wealth status than normotensive women (20.1\% vs $40.0 \%)$. The proportion of history of anemia was higher among women with $\mathrm{PIH}$ than normotensive women $(27.3 \%$ vs $10 \%)$. (Table 1).

\section{Incidence of adverse perinatal outcomes among study participants}

Nearly $66.4 \%$ of women with PIH and $22.2 \%$ of normotensive women developed adverse perinatal outcomes in their newborns. The incidence of birth asphyxia was higher among newborn babies delivered from women with $\mathrm{PIH}$ than normotensive women (46.5\% vs11.3\%). Similarly, low birth weight babies were higher among women with $\mathrm{PIH}$ than normotensive women $(37.7 \%$ vs $6.1 \%)$. The mean birth weight of babies born from women with PIH was $2647.2 \mathrm{~g}$ and $3176 \mathrm{~g}$ among normotensive pregnant women $(t-$ test $=-11.66, p$-value $<0.001$ ). In addition, $36.7 \%$ of babies born from women with $\mathrm{PIH}$ and $10.7 \%$ from normotensive women were small for gestational age. The proportions of admission to the neonatal intensive care unit were higher among newborns delivered from women with PIH than normotensive women (28.8\% vs 5.4\%). Additionally, higher preterm births occurred among pregnant women with $\mathrm{PIH}$ than normotensive pregnant women $(40.8 \%$ vs $5.6 \%)$. Women with PIH were more likely to have a lower gestational age at delivery than normotensive women $(37.3 \pm 2.5$ weeks vs. $39.0 \pm 1.6$ weeks, $p=0.001)$.

Stillbirths occurred in $10.0 \%$ of women with $\mathrm{PIH}$ and $1.7 \%$ normotensive pregnant women respectively. The stillbirth rate among women with PIH was 100/ 1000 live births.

Moreover, early neonatal death occurred in $5.0 \%$ of mothers with $\mathrm{PIH}$ and $1.0 \%$ of normotensive mothers. Overall perinatal death occurred in $15.0 \%$ women with $\mathrm{PIH}$ and $2.5 \%$ normotensive pregnant women. Similarly, the perinatal mortality rate among women with $\mathrm{PIH}$ was 150 per 1000 live births and 25 per 1000 live births among normotensive pregnant women (Fig. 2).

\section{Risk of adverse perinatal outcomes associated with pregnancy-induced hypertension}

The risk of birth asphyxia (adjusted relative risk $(\mathrm{aRR})=$ 2.69 , 95\%CI $(1.91,3.80))$, low birth weight $(\mathrm{aRR}=5.13$ $(3.36,7.84))$, preterm newborn $(\mathrm{aRR}=5.19(3.37,7.99))$, small for gestational age $(\mathrm{aRR}=3.3(2.3,4.6))$, admission to $\quad \mathrm{NICU} \quad(\mathrm{aRR}=3.29(2.33,4.65))$, stillbirth $\quad(\mathrm{aRR}=$ $3.46(1.40,8.54)$ ) and perinatal mortality $(\mathrm{aRR}=3.67(1.83$, 7.38)) were significantly higher in women with pregnancy-induced hypertension compared to normotensive women after adjusted by maternal age, wealth status, educational status, residence, gravidity, mode of delivery, anemia and maternal undernutrition status (Table 2).

\section{Discussion}

The aim of this study was to assess the effect of pregnancyinduced hypertension on adverse perinatal outcomes. Based on this we found that women with PIH showed a higher risk of adverse perinatal outcomes such as low birth weight, birth asphyxia, small for gestational age, preterm delivery, stillbirth, admission to NICU and perinatal death compared to normotensive pregnant women.

The burden of PIH is common in Ethiopia. Many mothers and newborns are affected by the adverse outcomes of PIH. There are many causes for this problem such as poor access to health service and quality of maternal and newborn care in Ethiopia. Therefore, the rationale for this study was to help policymakers and programmers to have a clear picture about the effect of $\mathrm{PIH}$ on adverse perinatal outcomes to make an evidence-based decision and mobilize resources for the management of PIH and its associated perinatal complications in the region. It will also guide health care providers working in clinical areas to make evidence-based decisions for the prevention and management of adverse perinatal outcomes of $\mathrm{PIH}$.

Specifically, findings of this study revealed that 37.7 and $40.8 \%$ of women with PIH delivered low birth weight (LBW) and preterm babies respectively. These findings were higher than the studies conducted in Ghana (24.7\% LBW and $21.7 \%$ preterm), India $(22.2 \%$ LBW and $24.6 \%$ preterm) and São Paulo city $(21.0 \%$ LBW and $10.6 \%$ preterm) [40-42]. The difference in the incidence of low birth weight and preterm birth across studies could be due to the difference in the quality of antenatal care service and management of PIH between the study areas. Similarly, there was higher risk of delivering low birth weight and preterm newborn babies among women with PIH compared to normotensive women, this might be due to intrauterine growth retardation as a result of placental insufficiency and due to the interventional delivery being carried out irrespective of the gestational age, especially on eclamptics to prevent further maternal and perinatal morbidity and mortality. Complications from preterm birth and low birth weight are the leading cause of child deaths every year, accounting for nearly one million deaths globally. Thus, preventing and/or managing $\mathrm{PIH}$ should become as one of the priority ways 
Table 1 Socio-demographic characteristics of pregnant women attending antenatal care in Tigray regional state, Ethiopia, 2019

\begin{tabular}{|c|c|c|c|}
\hline \multirow[t]{2}{*}{ Variable } & & \multirow{2}{*}{$\begin{array}{l}\text { Normotensive } \\
\text { Mean (SD) }\end{array}$} & \multirow{2}{*}{$\begin{array}{l}\text { Women with PIH } \\
\text { Mean (SD) }\end{array}$} \\
\hline & & & \\
\hline \multirow[t]{2}{*}{ Maternal Age (year) } & & $27.34(5.4)$ & $27.27(6.4)$ \\
\hline & & $N(\%)$ & $N(\%)$ \\
\hline \multirow[t]{2}{*}{ Residence } & Urban & $435(83.3)$ & $178(68.5)$ \\
\hline & Rural & $87(16.7)$ & $82(31.5)$ \\
\hline \multirow[t]{4}{*}{ Mothers educational status } & No formal education & $36(6.9)$ & $58(22.3)$ \\
\hline & Primary & $114(21.8)$ & $103(39.6)$ \\
\hline & Secondary & $188(36.0)$ & $62(23.8)$ \\
\hline & Diploma and above & $184(35.2)$ & $37(14.2)$ \\
\hline \multirow[t]{4}{*}{ Religious } & Orthodox & $459(87.9)$ & $214(82.3)$ \\
\hline & Catholic & $17(3.3)$ & $15(5.8)$ \\
\hline & Muslim & $38(7.3)$ & $26(10.0)$ \\
\hline & Protestant & $8(1.5)$ & $5(1.9)$ \\
\hline \multirow[t]{2}{*}{ Mothers occupation } & Unemployed & $250(47.9)$ & $201(77.3)$ \\
\hline & Employed & $272(52.1)$ & $59(22.7)$ \\
\hline \multirow[t]{3}{*}{ Wealth index } & Lowest & $120(23.3)$ & $138(53.3)$ \\
\hline & Middle & $189(36.7)$ & 69 (26.6) \\
\hline & Highest & $206(40.0)$ & $52(20.1)$ \\
\hline \multirow[t]{8}{*}{ Hospitals } & Lemlem Carl & $59(11.3)$ & $29(11.2)$ \\
\hline & Mekelle & $78(14.9)$ & $39(15)$ \\
\hline & Wukro & $50(9.6)$ & $24(9.2)$ \\
\hline & Adigrat & $78(14.9)$ & $39(15)$ \\
\hline & Adwa & $53(10.2)$ & $28(10.8)$ \\
\hline & Saint Marry Axum & $79(15.1)$ & $39(15)$ \\
\hline & Suhul Shire & $70(13.4)$ & $35(13.5)$ \\
\hline & Kahsay Abera & $55(10.5)$ & $27(10.4)$ \\
\hline \multirow[t]{3}{*}{ Gravidity } & Primigravida & $166(31.8 \%)$ & $107(41.2 \%)$ \\
\hline & 2-4 gravida & $299(57.3 \%)$ & $118(45.4 \%)$ \\
\hline & $\geq 5$ gravida & 57 (10.9\%) & $35(13.5 \%)$ \\
\hline \multirow[t]{2}{*}{ History of anemia } & Yes & $52(10 \%)$ & $71(27.3 \%)$ \\
\hline & No & 470 (90\%) & $189(72.7 \%)$ \\
\hline \multirow[t]{2}{*}{ Maternal undernutrition } & Yes & $119(22.8 \%)$ & $63(24.2 \%)$ \\
\hline & No & $403(77.2 \%)$ & $197(75.8 \%)$ \\
\hline \multirow[t]{2}{*}{ Type of pregnancy } & Singleton & $517(99.0 \%)$ & $245(94.2 \%)$ \\
\hline & Multiple & $5(1.0 \%)$ & $15(5.8 \%)$ \\
\hline \multirow[t]{3}{*}{ Prior history of PIH } & Yes & $9(1.7 \%)$ & $28(12.7 \%)$ \\
\hline & No & $509(98.3 \%)$ & $192(87.3 \%)$ \\
\hline & & Median (IQR) & Median (IQR) \\
\hline Gestational age at enrollment (in weeks) & & $31( \pm 3.25)$ & $31( \pm 4)$ \\
\hline
\end{tabular}

of reducing the risk of low birth weight and preterm births as well as their associated consequences. Additionally, to improve the outcome of those premature newborn infants, health care providers should strengthen kangaroo mother care including thermal care (skin-to-skin contact), family support for the mother-infant, exclusive and frequent breastfeeding.

In addition, the incidence of birth asphyxia among newborn babies born from women with PIH was $39.6 \%$. This finding was higher compared to studies conducted 


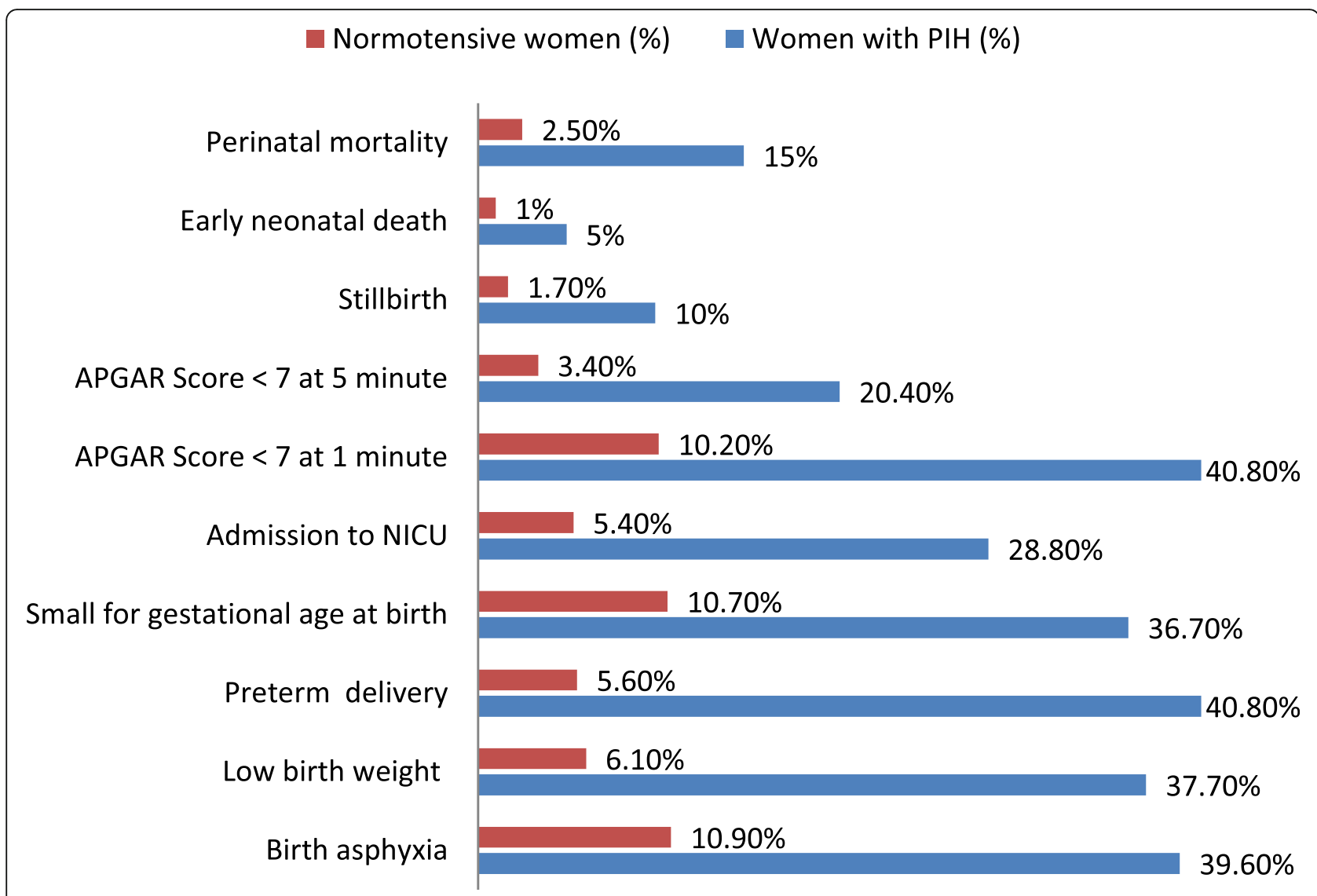

Fig. 2 Adverse perinatal outcomes among women with PIH $(n=260)$ and normotensive pregnant women $(n=522)$ in Tigray Regional State, Ethiopia 2019

in Amhara Region, Ethiopia(10.1\%), Ghana (15.2\%), India (27.1\%), Uganda (21.8\%) and Turkey (28.9\%) [24, $26,40,41,43]$. Additionally, the risk of birth asphyxia among newborns born from women with PIH was higher; this might be related to a decrease in the uteroplacental blood flow resulting from increased blood pressure [28]. Also, the risk of preterm birth of babies among women with PIH might be vulnerable to the immaturity of muscle tone and reflex irritability. In premature newborns, the lungs may be deficient in surfactant and this makes the lung more difficult to ventilate. Hence, neonatal resuscitation skilled health care providers should be assigned to every delivery service. In addition, all necessary types of equipment needed for resuscitation should be ready at every delivery by anticipating the risk of birth asphyxia among women with PIH since newborns that do not start breathing on their own by 1 min after birth should receive positive pressure ventilation with room air by a self-inflating bag and mask.

Further, the incidence of small for gestational age of newborns was $36.7 \%$ among women with PIH. This was higher than the study reports from Ghana (6.3\%),
Madagascar (25.7\%), and South Africa (17\%) [40, 44, 45]. The difference across studies might be related to the utilization of antenatal care services across countries. For instance, a study conducted in Ghana indicated that a higher proportion of pregnant women were completed four or more antenatal care visits compared to a study conducted in Ethiopia (41.3\% vs 33.0\%) [46, 47]. Moreover, the risk of small for gestational age newborns was higher among women with PIH; this could be related with intrauterine growth retardation due to a decrease of uteroplacental blood flow and the development of ischemia in women with pregnancy-induced hypertension. Thus, women with PIH should attend their delivery in facilities having neonatology skilled professional and necessary material for managing small for gestational age babies. Additionally, health care providers should provide immediate and adequate care for newborn infants with SGA to prevent further adverse effects of a newborn like hypoglycemia, hypothermia and feeding problems.

In this study, approximately one-third (28.8\%) of the newborns delivered from women with PIH were admitted to the neonatal intensive care unit (NICU). This 
Table 2 Bivariate and multivariate Poisson regression analysis on the association between PIH and adverse perinatal outcomes in Tigray regional state, Ethiopia, 2018/2019

\begin{tabular}{|c|c|c|c|c|c|}
\hline Perinatal outcome indicators & & $\begin{array}{l}\text { Pregnancy-induced hypertension } n= \\
260\end{array}$ & $\begin{array}{l}\text { Normotensive women } n= \\
522\end{array}$ & $\begin{array}{l}\text { Unadjusted RR (95\% } \\
\text { Cl) }\end{array}$ & $\begin{array}{l}\text { Adjusted RR (95\% } \\
\text { Cl) }\end{array}$ \\
\hline \multirow[t]{2}{*}{ Birth asphyxia } & Yes & $103(39.6 \%)$ & 57 (10.9\%) & $3.62(2.72,4.83)$ & $2.69(1.91,3.80)$ \\
\hline & No & $157(60.4)$ & $465(89.1)$ & 1 & 1 \\
\hline \multirow[t]{2}{*}{ Low birth weight } & Yes & 98 (37.7\%) & $32(6.1 \%)$ & $6.14(4.24,8.90)$ & $5.13(3.36,7.84)$ \\
\hline & No & $162(62.3)$ & $490(93.9)$ & 1 & 1 \\
\hline \multirow[t]{2}{*}{ Preterm delivery } & Yes & $106(40.8 \%)$ & $29(5.6 \%)$ & $7.33(5.00,10.76)$ & $5.19(3.37,7.99)$ \\
\hline & No & $154(59.2)$ & $493(94.4)$ & 1 & 1 \\
\hline \multirow{2}{*}{$\begin{array}{l}\text { Small for gestational age at } \\
\text { birth }\end{array}$} & Yes & 95 (36.7\%) & $56(10.7 \%)$ & $3.41(2.54,4.59)$ & $3.29(2.33,4.65)$ \\
\hline & No & $164(63.3)$ & $466(89.3)$ & 1 & 1 \\
\hline \multirow[t]{2}{*}{ Admission to NICU } & Yes & 75 (28.8\%) & $28(5.4 \%)$ & $5.37(3.57,8.08)$ & $5.11(3.10,8.40)$ \\
\hline & No & $185(71.2)$ & $494(94.6)$ & 1 & 1 \\
\hline \multirow[t]{2}{*}{ Apgar Score $<7$ at $1 \mathrm{~min}$} & Yes & $106(40.8 \%)$ & $53(10.2 \%)$ & $4.01(2.99,5.39)$ & $2.93(2.06,4.17)$ \\
\hline & No & $106(40.8)$ & $53(10.2)$ & 1 & 1 \\
\hline \multirow[t]{2}{*}{ Apgar Score < 7at 5 min } & Yes & $53(20.4 \%)$ & $18(3.4 \%)$ & $5.91(3.53,9.88)$ & $3.78(2.05,6.97)$ \\
\hline & No & $207(79.6)$ & $504(96.6)$ & 1 & 1 \\
\hline \multirow[t]{2}{*}{ Stillbirth } & Yes & $26(10.0 \%)$ & $9(1.7 \%)$ & $5.79(2.75,12.20)$ & $3.46(1.40,8.54)$ \\
\hline & No & $234(90.0)$ & $513(98.3)$ & 1 & 1 \\
\hline \multirow[t]{2}{*}{ Early neonatal death } & Yes & $13(5.0 \%)$ & $5(1.0 \%)$ & $5.22(1.87,14.49)$ & $3.22(1.06,9.74)$ \\
\hline & No & $247(95.0)$ & $517(99.0)$ & 1 & 1 \\
\hline \multirow[t]{2}{*}{ Perinatal mortality } & Yes & 39 (15.0\%) & $13(2.5 \%)$ & $6.02(3.27,11.08)$ & $3.67(1.83,7.38)$ \\
\hline & No & $221(85.0)$ & $509(97.5)$ & 1 & \\
\hline
\end{tabular}

$R R$ Relative Risk; ${ }^{*}$ the adverse perinatal outcomes were adjusted for maternal age, wealth status, educational status, residence, gravidity, type of pregnancy and mode of delivery, anemia status, maternal undernutrition $1=$ reference group

finding was higher than studies conducted in Iran (13\%) and Minia maternity hospital, Egypt (18.8\%) [30, 48]. The higher risk of newborn baby admission to NICU among newborns delivered from women with PIH compared to newborn delivered from normotensive women could be related to the higher adverse effect of PIH on low birth weight, birth asphyxia, and preterm births.

The incidence of stillbirth among women with PIH in this study was $10 \%$. This result was more or less consistent with the study conducted in Mizan Tepi, Ethiopia (9.1\%) and Mettu, Ethiopia (10\%) [27, 49], but the finding of this study was higher than the study conducted in Zimbabwe (5.4\%), Ghana (6.8\%) [23, 40]. This difference could be due to the difference in the quality of antenatal care and obstetric care service among health care institutions. The increased risk of stillbirth among women with PIH might be related with the effect of decreased uteroplacental blood flow and placental ischemia related to $\mathrm{PIH}$ which compromises blood flow to the fetus [50, 51].

Similarly, the result of this study revealed that perinatal death occurred in $15.0 \%$ of women with PIH. This finding was more or less consistent with the study conducted in Mettu Karl Referral Hospital, Ethiopia (12.04\%) [27]. However, the finding of this study was higher than a study conducted in Ghana (10.6\%), PortHarcourt, Nigerian (7.6\%), Madagascar (8.7\%) and University college hospital, Ibadan (10\%) [40, 52, 53]. The difference in the incidence of perinatal death across studies could be due to the difference in the quality of care for antenatal care, intrapartum and newborn care among health care facilities. This finding is far higher from the targeted global plan of sustainable development goal (SDG) to reduce neonatal mortality to less than 12 per 1000 live births and national health sector transformation plan to reduced $15 / 1000$ live births [54, 55]. This indicates the necessity of Ethiopia federal ministry of health and Tigray regional health bureau to strengthen maternal and newborn health care in order to achieve the targeted global and national SDG plan by focusing interventions on the determinants of perinatal mortality such as pregnancy-induced hypertension.

The prospective nature of the study considered as a strength of this study in reducing the incompleteness of data and less bias in misclassification due to the prospective evaluation of exposures and outcomes. We have enrolled the participants at 28-35 weeks of gestational age. The reasons why we did not include women who developed PIH before 28 weeks in this study were; i) the 
number of women who develop PIH before 28 weeks is likely to be very small $[10,56]$; ii) those women who develop PIH early could be more likely to have more complications and this might overestimate the rates of complications in the PIH group [56, 57].

Similarly, the reasons to exclude the pregnant women after 36 weeks was; i) to see all adverse perinatal outcomes over a long period of time before the mother gives birth, ii) another reason was also due to the management protocols of $\mathrm{PIH}$, after 36 weeks of gestational age obstetrician could manage with elective/emergency cesarean section [58], so this condition may underestimate the adverse perinatal outcomes especially stillbirth.

As a limitation, matching criteria were not used to identify normotensive women this could reduce the comparability of the outcomes, the tertiary hospital in Tigray regional state was not included in this study; this might have some effect on the burden of adverse perinatal outcomes of PIH.

\section{Conclusions}

Higher incidences of adverse perinatal outcomes occurred among women with pregnancy-induced hypertension in Tigray regional state, Ethiopia. Pregnancyinduced hypertension was associated with a higher risk of adverse perinatal outcomes such as low birth weight, birth asphyxia, small for gestational age, preterm delivery and perinatal death. Tigray Regional Health Bureau and district health offices should use this evidence to improve perinatal health outcomes in collaboration with other stakeholders. In addition, health care providers should strengthen the primary and secondary prevention, early diagnosis and prompt management of pregnancy-induced hypertension to reduce the incidence of adverse perinatal outcomes of pregnancy-induced hypertension. This study addresses women diagnosed with preeclampsia, eclampsia and gestational hypertension between 28 and 35 weeks of gestation. Hence, we recommended researchers to conducted further study about the effect of early (before 28 wks) and late (after 36 wks) pregnancy-induced hypertension on the adverse fetal outcomes.

\section{Abbreviation \\ Apgar score: Appearance, Pulse, Grimace, Activity, and Respiration score; APH: Antepartum hemorrhage; aRR: Adjusted Relative Risk; BP: Blood Pressure; EDHS: Ethiopia Demographic Health Survey; LBW: Low birth weight; NICU: Neonatal Intensive Care Unit; PIH: Pregnancy Induced Hypertension; RR: Crude relative risk; SGA: Small for gestational age; WHO: World Health Organization}

\section{Acknowledgments}

We would like to thank Pan African University of Life and earth sciences Institute, African Union for financial support and University of Ibadan for hosting this Ph.D. program.

Our gratitude also goes to data collectors and supervisors for their diligence during data collection to obtain necessary information. Our special thanks also go to participants who generously shared their thoughts and feelings despite other commitments. In addition, our thanks goes to Tigray regional health bureau and administrators of all hospitals included in this study for giving us the necessary background information to conduct this study.

\section{Authors' contributions}

AKB was the principal author who participated in the conceptualization, design, acquisition, analysis, and interpretation of the data and drafted the manuscript and acted as the corresponding author. AOI was the primary academic advisor, contributed to design, acquisition, analysis, and interpretation of the data and critically revised the manuscript. COA \& AMB were co-advisors, contributed to design, acquisition, analysis, and interpretation of the data and critically revised the manuscript for important intellectual content. All authors read and approved the final manuscript.

\section{Funding}

The source of funding to carry out for this research was from Pan African University of Life and earth sciences Institute, Pan African University, African Union. The funding organization has no role in the design of the study and collection, analysis, and interpretation of data and in writing the manuscript, this was the role of authors.

\section{Availability of data and materials}

The datasets used and/or analyzed during this study are available from the corresponding author on reasonable request.

\section{Ethics approval and consent to participate}

Ethical approval and clearance for this study was obtained from the University of Ibadan, University College Hospital / $\mathrm{CH} /$ institutional ethical review committee (Ref.NHREC/05/01/2008a). An official letter of cooperation was getting from Tigray Regional State Health Bureau to selected hospitals. Permission from each Chief Executive Officer of the hospitals was received too. Data collectors approached individually the study participants who were given information regarding the purpose of the study, confidentiality of study, their right to participate or withdraw from the study. Finally, written consent was obtained from the study participants.

\section{Consent for publication}

Not applicable.

\section{Competing interests}

The authors declare that they have no competing interests.

\section{Author details}

${ }^{1}$ College of Medicine and Health Sciences, Adigrat University, Tigray, Ethiopia. ${ }^{2}$ Pan African University Institute for Life and Earth Sciences, University of Ibadan, Ibadan, Nigeria. ${ }^{3}$ Department of Obstetrics and Gynaecology, College of Medicine, University College Hospital, University of Ibadan, Ibadan, Nigeria. ${ }^{4}$ School of Public Health, College of Health Sciences, Mekelle University, Tigray, Ethiopia.

Received: 11 September 2019 Accepted: 26 December 2019 Published online: 31 December 2019

\section{References}

1. Zhang J, Zeisler J, Hatch MC, Berkowitz G. Epidemiology of pregnancyinduced hypertension. Epidemiol Rev. 1997;19(2):218-32.

2. Xiong $X$, Fraser WD. Impact of pregnancy-induced hypertension on birthweight by gestational age. Paediatr Perinat Epidemiol. 2004;18(3):18691.

3. Chen X-K, Wen SW, Smith G, Yang Q, Walker M. Pregnancy-induced hypertension and infant mortality: roles of birthweight centiles and gestational age. BJOG Int J Obstet Gynaecol. 2007;114(1):24-31.

4. Magee LA, von Dadelszen P, Peter V, William S, Matthews M. he FIGO Textbook of Pregnancy Hypertension: An evidence-based guide to monitoring, prevention and management. The Global Library of Women's Medicine, London. "Retrieved Auguest 19,2017, from https://www.glowm. com/resource_type/resource/textbook/title/the-figo-textbook-of-pregnancyhypertension/resource doc/2768 "2016.

5. US National High Blood Pressure Education. program. Report of the national high blood pressure education program working group on high blood pressure in pregnancy. Am J Obstet Gynecol. 2000;183(1):s1-s22. 
6. North RA, McCowan LM, Dekker GA, Poston L, Chan EH, Stewart AW, et al. Clinical risk prediction for pre-eclampsia in nulliparous women: development of model in international prospective cohort. BMJ. 2011;342:d1875.

7. Osungbade $\mathrm{KO}$, Ige OK. Public health perspectives of preeclampsia in developing countries: implication for health system strengthening. J Pregnancy. 2011;2011:481095

8. Abate M, Lakew Z. Eclampsia a 5 years retrospective review of 216 cases managed in two teaching hospitals in Addis Ababa. Ethiop Med J. 2006; 44(1):27-31

9. Mekbeb T, Ketsela K. Pre-eclampsia/eclampsia at Yekatit 12 hospital, Addis Ababa, Ethiopia (1987-1989). East Afr Med J. 1991;68(11):893-9.

10. Vata PK, Chauhan NM, Nallathambi A, Hussein F. Assessment of prevalence of preeclampsia from Dilla region of Ethiopia. BMC Research Notes. 2015; 8(1):816.

11. Wolde Z, Segni H, Woldie M. hypertensive disorders of pregnancy in Jimma University Specialized Hospital. Ethiop J Health Sci. 2011;21(3):147-54.

12. Teklu S, Gaym A. Prevalence and clinical correlates of the hypertensive disorders of pregnancy at Tikur Anbessa hospital, Addis Ababa, Ethiopia. Ethiop Med J. 2006:44(1):17-26

13. Shegaze M, Markos Y, Estifaons W, Taye I. Magnitude and Associated Factors of Preeclampsia Among Pregnant Women who Attend Antenatal Care Service in Public Health Institutions in Arba Minch Town, Southern Ethiopia, 2016. Gynecol Obstet. 2016:6(12):1-6.

14. Godefay H, Byass P, Kinsman J, Mulugeta A. Understanding maternal mortality from top-down and bottom-up perspectives: Case of Tigray Region, Ethiopia. J Glob Health. 2015;5(1):1-8.

15. Godefay H, Byass P, Graham WJ, Kinsman J, Mulugeta A. Risk Factors for Maternal Mortality in Rural Tigray, Northern Ethiopia: A Case-Control Study. PLoS One. 2015;10(12):e0144975.

16. Berhe AK, Kassa GM, Fekadu GA, Muche AA. Prevalence of hypertensive disorders of pregnancy in Ethiopia: a systemic review and meta-analysis. BMC Pregnancy Childbirth. 2018;18(1):34.

17. Kampruan R, Sukonpan K, Wasinghon P. Pregnancy outcomes amongst normotensive and severe preeclampsia with or without underlying chronic hypertension pregnancy. Thai J Obstet Gynaecol. 2016;24(3):202-8.

18. Raghuraman N, March Ml, Hacker MR, Modest AM, Wenger J, Narcisse R, et al. Adverse maternal and fetal outcomes and deaths related to preeclampsia and eclampsia in Haiti. Pregnancy Hypertens. 2014;4(4):279-86.

19. Duley L. The global impact of pre-eclampsia and eclampsia. Semin Perinatol. 2009;33(3):130-7.

20. Ngoc NTN, Merialdi M, Abdel-Aleem H, Carroli G, Purwar M, Zavaleta N, et al. Causes of stillbirths and early neonatal deaths: data from 7993 pregnancies in six developing countries. Bull World Health Organ. 2006; 84(9):699-705

21. Kolluru V, Harika R, Kaul R. Maternal and perinatal outcome associated with pregnancy induced hypertension. Int J Reprod Contracept Obstet Gynecol. 2016;5(10):3367-71.

22. Liu C-M, Cheng P-J, Chang S-D. Maternal complications and perinatal outcomes associated with gestational hypertension and severe preeclampsia in Taiwanese women. J Formos Med Assoc. 2008;107(2):129-38.

23. Muti M, Tshimanga M, Notion GT, Bangure D, Chonzi P. Prevalence of pregnancy induced hypertension and pregnancy outcomes among women seeking maternity services in Harare, Zimbabwe. BMC Cardiovasc Disord. 2015;15:111.

24. Kiondo P, Tumwesigye NM, Wandabwa J, Wamuyu-Maina G, Bimenya GS, Okong P. Adverse neonatal outcomes in women with pre-eclampsia in Mulago Hospital, Kampala, Uganda: a cross-sectional study. Pan Afr Med J. 2014;17(Suppl 1):1-5.

25. Nathan HL, Seed PT, Hezelgrave NL, De Greeff A, Lawley E, Conti-Ramsden $F$, et al. Maternal and perinatal adverse outcomes in women with preeclampsia cared for at facility-level in South Africa: a prospective cohort study. J Glob Health. 2018;8(2):1-10.

26. Melese MF, Badi MB, Aynalem GL. Perinatal outcomes of severe preeclampsia/eclampsia and associated factors among mothers admitted in Amhara region referral hospitals, North West Ethiopia, 2018. BMC Res Notes. 2019;12(1):147

27. Seyom E, Abera M, Tesfaye M, Fentahun N. Maternal and fetal outcome of pregnancy related hypertension in Mettu Karl referral hospital, Ethiopia. J Ovarian Res. 2015;8:10

28. Chen XK, Wen SW, Smith G, Yang Q, Walker M. Pregnancy-induced hypertension is associated with lower infant mortality in preterm singletons. BJOG. 2006;113(5):544-51.
29. Ethiopia CSA, Macro ORC. Demographic and health survey 2016. Addis Ababa: Central Statistical Agency, Addis Ababa, Ethiopia; 2016.

30. Fatemeh T, Marziyeh G, Nayereh G, Anahita G, Samira T. Maternal and perinatal outcome in nulliparious women complicated with pregnancy hypertension. J Pak Med Assoc. 2010;60(9):707.

31. Hailemariam B. Pre-clampsia and its outcome (maternal and neonatal morbidity and mortality) in the two referral hospitals (Windhoek Central and Katutura), Namibia.

32. Hossain N, Shah N, Khan N, Lata S, Khan NH. Maternal and Perinatal outcome of Hypertensive Disorders of Pregnancy at a Tertiary care Hospital. J Dow Univ Health Sci. 2015;5(1):12-16.

33. Paknahad Z, Talebi N, Azadbakht L. Dietary determinants of pregnancy induced hypertension in Isfahan. J Res Med Sci. 2008;13(1):17-21.

34. WHO. WHO STEPS surveillance manual: the WHO STEPwise approach to chronic disease risk factor surveillance. 2005.

35. Endeshaw G, Berhan Y. Perinatal outcome in women with hypertensive disorders of pregnancy: a retrospective cohort study. Inter Sch Res Notices. 2015;2015:208043

36. Tessema GA, Tekeste A, Ayele TA. Preeclampsia and associated factors among pregnant women attending antenatal care in Dessie referral hospital, Northeast Ethiopia: a hospital-based study. BMC Pregnancy Childbirth. 2015;15(1):73.

37. World Health Organization. Definition of stillbirth accessed at https://www.who. int/maternal_child_adolescent/epidemiology/stillbirth/en/ on date 27/10/2019.

38. WHO. The ICD-10 classification of mental and behavioural disorders: clinical descriptions and diagnostic guidelines. Geneva: World Health Organization; 1992.

39. Brenner WE, Edelman DA, Hendricks $\mathrm{CH}$. A standard of fetal growth for the United States of America. Am J Obstet Gynecol. 1976;126(5):555-64.

40. Adu-Bonsaffoh K, Ntumy MY, Obed SA, Seffah JD. Perinatal outcomes of hypertensive disorders in pregnancy at a tertiary hospital in Ghana. BMC Pregnancy Childbirth. 2017;17(1):388.

41. Badal S, Singh LR. Maternal and perinatal outcome in severe pre-eclampsia and eclampsia. World J Pharm Med Res. 2017;3(3):193-5.

42. Chaim SRP, Oliveira SMJV, Kimura AF. Pregnancy-induced hypertension and the neonatal outcome. Acta Paulista de Enfermagem. 2008;21(1):53-8.

43. Yucesoy G, Ozkan S, Bodur H, Tan T, Caliskan E, Vural B, et al. Maternal and perinatal outcome in pregnancies complicated with hypertensive disorder of pregnancy: a seven year experience of a tertiary care center. Arch Gynecol Obstet. 2005;273(1):43-9.

44. Poonyane T. Impact of severe preeclampsia on maternal and fetal outcomes in preterm deliveries; 2015

45. Randriamahavonjy RTR, Andrianirina ZZ, Andrianampanalinarivo HR. Materno-fetal outcomes in pre eclampsia in a rural hospital of Antananarivo Madagascar. Int J Res Med Sci. 2018;6(4):1064-7.

46. Muchie KF. Quality of antenatal care services and completion of four or more antenatal care visits in Ethiopia: a finding based on a demographic and health survey. BMC Pregnancy Childbirth. 2017:17(1):300.

47. Sumankuuro J, Crockett J, Wang S. The use of antenatal care in two rural districts of upper west region, Ghana. PLoS One. 2017:12(9):e0185537.

48. Mahran A, Fares H, Elkhateeb R, Ibrahim M, Bahaa H, Sanad A, et al. Risk factors and outcome of patients with eclampsia at a tertiary hospital in Egypt. BMC Pregnancy Childbirth. 2017;17(1):435

49. RT GTA. Prevalence of Pregnancy Induced Hypertension and Its Bad Birth Outcome among Women Attending Delivery Service. J Preg Child Health. 2017:4(335):1-4.

50. Granger JP, Alexander BT, Bennett WA, Khalil RA. Pathophysiology of pregnancy-induced hypertension. Am J Hypertens. 2001;14(S3):178S-85S.

51. Gilbert JS, Ryan MJ, LaMarca BB, Sedeek M, Murphy SR, Granger JP. Pathophysiology of hypertension during preeclampsia: linking placental ischemia with endothelial dysfunction. Am J Phys Heart Circ Phys. 2008; 294(2):H541-H50.

52. George 10 , Jeremiah I. Perinatal outcome of babies delivered to eclamptic mothers: a prospective study from a Nigerian tertiary hospital. Int J Biomed Sci. 2009:5(4):390.

53. Randriamahavonjy $\mathrm{R}$, Tsifiregna $\mathrm{RL}$, Andrianirina ZZ, Andrianampanalinarivo HR. Materno-fetal outcomes in pre eclampsia in a rural hospital of Antananarivo Madagascar. Int J Res Med Sci. 2018;6(4):1064-7.

54. Kumar S, Kumar N, Vivekadhish S. Millennium development goals (MDGs) to sustainable development goals (SDGs): addressing unfinished agenda and strengthening sustainable development and partnership. Indian J Community Med. 2016;41(1):1-4. 
55. Health FMo. Health Sector Transformation Plan (2015/16-2019/20). Ethiopia: Federal Ministry of Health Addis Ababa; 2015.

56. Ebeigbe P, Aziken ME. Early onset pregnancy induced hypertension/ eclampsia in Benin City, Nigeria. Niger J Clin Pract. 2010;13(4):388-93.

57. Onah H, lloabachie G. Conservative management of early-onset preeclampsia and fetomaternal outcome in Nigerians. J Obstet Gynaecol. 2002; 22(4):357-62.

58. Health FMo. Basic Emergency Obstetric \& Newborn Care (BEmONC) training manual. 2014.

\section{Publisher's Note}

Springer Nature remains neutral with regard to jurisdictional claims in published maps and institutional affiliations.

Ready to submit your research? Choose BMC and benefit from:

- fast, convenient online submission

- thorough peer review by experienced researchers in your field

- rapid publication on acceptance

- support for research data, including large and complex data types

- gold Open Access which fosters wider collaboration and increased citations

- maximum visibility for your research: over $100 \mathrm{M}$ website views per year

At $\mathrm{BMC}$, research is always in progress.

Learn more biomedcentral.com/submissions 